\title{
Adriamycin-loaded albumin-heparin conjugate microspheres for intraperitoneal chemotherapy
}

\author{
H.F.M. Cremers ${ }^{\text {a }}$, L.W. Seymour ${ }^{\text {b }}$, K. Lam ${ }^{\text {c }}$, G. Los ${ }^{\mathrm{d}}$, M. van Vugt ${ }^{\mathrm{d}}$, G. Kwon ${ }^{\mathrm{e}}$, \\ Y.H. Bae ${ }^{\text {e }}$, S.W. Kim ${ }^{\text {e }}$, J. Feijen ${ }^{\text {a,* }}$ \\ ${ }^{a}$ Department of Chemical Technology, University of Twente, P.O. Box 217, 7500 AE Enschede, The Netherlands \\ ${ }^{b}$ Cancer Research Campaign's Polymer-Controlled Drug Delivery Research Group, Department of Biological Sciences, \\ University of Keele, Keele ST5 $5 B G, U K$ \\ ${ }^{\circ}$ Department of Histology and Cell Biology, University of Groningen, Oostersingel 69/2, 9713 EZ Groningen, The Netherlands \\ ${ }^{\mathrm{d}}$ Division of Experimental Therapy, The Netherlands Cancer Institute, Plesmanlaan 121, 1066 CX Amsterdam, The Netherlands \\ 'Department of Pharmaceutics and Center for Controlled Chemical Delivery, University of Utah, 421 Wakaraway, Suite 318 , \\ Salt Lake City, UT 84108, USA
}

Received 17 January 1994; accepted 21 March 1994

\begin{abstract}
Adriamycin-loaded albumin-heparin conjugate microspheres (ADR-AHCMS) were evaluated as possible intraperitoneal (i.p.) delivery systems for site-specific cytotoxic action. The biocompatibility of the microspheres after intraperitoneal injection was tested first. 1 day after i.p. administration of empty as well as drug-loaded AHCMS to male Balb/c mice, only a moderate increase in i.p. neutrophils was measured. 3 days after injection neutrophil levels were comparable with the controls. No significant increases in the numbers of other cell types were observed, indicating an acute inflammatory response which can be considered to be mild. Antitumour efficacy was tested in an L1210 tumour-bearing mouse model and in a CC531 tumour-bearing rat model. The use of ADR-AHCMS leads to longer survival times of mice and improved tumour growth delay in rats, as compared with untreated controls and free drug treated animals. In both animal models higher adriamycin doses were initially tolerated if the drug was formulated in microspheres, although long-term adriamycin toxicity effects were evident in all treated groups. Doses and dosage schedules may be optimized to further reduce the toxic effects of the drug.
\end{abstract}

Key words: Adriamycin; Microsphere; Biocompatibility; Intraperitoneal chemotherapy; Controlled release; Drug targeting

\section{Introduction}

In certain applications regional chemotherapy is established for elevating the therapeutic in-

\footnotetext{
* Corresponding author: Tel: +3153892968 ; Fax: +3153 330145 .
}

dices of conventional anticancer drugs. In the case of intracavitary malignancies, like brain tumours and regionalized abdominal pelvic or mediastinal cancer, intracavitary administration of therapeutic agents allows higher drug levels at the site of the tumour than could be achieved with systemic chemotherapy (Knapp et al., 1983). 
In the treatment of brain tumours the blood brain barrier is by-passed if the drugs are administered intracranially. Intracranial administration of drugs by means of refillable silicon devices (Ueno et al., 1982) or by using chronically implanted catheters (Bouvier et al., 1987) to treat brain tumours has been reported. Biodegradable polyanhydride discs loaded with bis(2-chlorocthyl)-1-nitrosurca (BCNU), implanted intracranially after surgical resection of the primary tumour, appear to be more effective than standard intravenous treatments (Brem, 1990; Langer, 1991). Another example of intracavitary chemotherapy is the intrapleural administration of cytarabine in the treatment of malignant pleural effusions (Markman and Howell, 1987).

Intraperitoneal (i.p.) chemotherapy for the treatment of malignant diseases that remain largely confined there (e.g., ovarian carcinoma) has also been widely investigated. In the clinical situation prolonged infusions of drugs have been used. Using a dialysis catheter, high intracavitary concentrations of drug can be achieved and large volumes of fluid can be instilled, permitting treatment of all peritoneal surfaces (Knapp et al., 1983; Regelson, 1986). The results have been promising though not spectacular, since most drugs are transferred rapidly out of the peritoneal cavity (Wahl et al., 1988). Upon entering the systemic circulation via either the portal route or the lymphatic route, systemic toxicity is inevitable. Markman and Howell (1987), however, mention that i.p. cytarabine, which mainly exits the peritoneal cavity via the portal circulation, is inactivated in the liver before entering the systemic circulation. Another approach is the co-administration of neutralizing agents via the intravenous route to neutralize the drug transferred from the peritoneal cavity into the bloodstream. Systemic toxicity of i.p. cisplatin, for instance, can be neutralized by systemic thiosulphate (Howell et al., 1982).

An alternative approach in i.p. chemotherapy has been the use of implantable drug delivery systems, designed for retention within the peritoneal cavity following administration there. Upon intracavitary implantation the drug can be released over an appropriate period. Heller et al.
(1991) developed bioerodible, 5-FU-loaded poly (ortho ester) devices which, after i.p. implantation, prolonged survival times of $\mathrm{DBA}_{2}$ mice inoculated i.p. with $\mathrm{L} 1210$ cells. Ulbrich et àl. (1992) studied the in vivo release of targeted and non-targeted adriamycin conjugates from intraperitoneally implanted, biodegradable hydrogels. A disadvantage which these systems have in common is that laparotomy is needed to implant the device.

Injectable formulations based on soluble polymers, synthesized for selective retention within the compartment, can be administered without surgery. Their application relies on physical size to regulate their drainage into the systemic circulation. Physical size (i.e., molecular mass) of soluble materials, however, is unable to mediate selective retention, materials up to $778 \mathrm{kDa}$ showing uninhibited lymphatic transfer into the bloodstream (Seymour et al., 1987).

One possible solution is the use of injectable formulations of particles, large enough to be selectively retained in the compartment but small enough to be injected without laparotomy. Albumin-heparin conjugate microspheres (AHCMS) loaded with adriamycin (ADR) appear to be ideal for this purpose because they can be synthesized in any appropriate size (Cremers et al., 1990, 1993a; Kwon et al., 1991) and they are known to release the drug in vitro by an ion exchange mechanism within a few hours after injection. The literature suggests that particles up to a diameter of $5 \mu \mathrm{m}$ are transferred relatively easily out of the compartment, with reports of some transfer of materials up to $22.5 \mu \mathrm{m}$ (Allen, 1956). Previously, Miyazaki et al. (1986) reported reduced toxicity and increased antitumour activity of ADR formulated in relatively small fibrinogen microspheres $(1.7 \pm 0.7 \mu \mathrm{m})$ in an Ehrlich ascites carcinoma-bearing mouse model. In this paper the evaluation of ADR-AHCMS with a mean particle size of $23 \mu \mathrm{m}$ as i.p. targeting devices against i.p. localized tumours is described.

The i.p. biocompatibility of empty and drugloaded particles was tested in a slightly modified version of the intraperitoneal biocompatibility test described by Pizzoferrato et al. (1987). Antitumour efficacy was determined in two different 
animal models. The first tumour model system used, intrapcritoncal L1210 lcukacmia, is long established and routinely employed for the screening of novel anticancer agents (Duncan et al., 1988) and polymeric drug delivery implants (Heller et al., 1991). In the second study, a single intraperitoneal tumour model in the rat was used (Los et al., 1990). The tumour used, CC531, is a carcinoma originating in the colon of a rat exposed to methylazoxymethanol (Zedeck and Sternberg, 1974).

\section{Materials and methods}

\subsection{Materials}

Albumin-heparin conjugate (AHC) containing $10.9 \% \mathrm{w} / \mathrm{w}$ of heparin was synthesized and purified according to procedures developed by Hennink et al. (1983). Highly refined olive oil was obtained from Sigma Chemical Co., St Louis, U.S.A. Glutaraldehyde (25\% aqueous solution), obtained from Merck, Darmstadt, Germany, was purified by distillation and adjusted to $2.5 \% \mathrm{w} / \mathrm{v}$ aqueous solutions prior to use (Gillett and Gull, 1972). Adriamycin was a kind gift from Farmitalia Carlo Erba, Milan, Italy. All other reagents were obtained, in the highest possible grade, from Merck, Darmstadt, Germany.

\subsection{Microsphere preparation and drug loading}

AHCMS were prepared as described before (Cremers et al., 1990, 1993a). Briefly, to $125 \mathrm{ml}$ of prestirred $(850 \mathrm{rpm})$ olive oil, $0.6 \mathrm{ml}$ of a conjugate solution in phosphate-buffered saline $(100$ $\mathrm{mg} / 0.6 \mathrm{ml}$ PBS) was added. After emulsification for $15 \mathrm{~min}, 0.15 \mathrm{ml}$ of glutaraldehyde solution was added. The emulsion was stirred at $850 \mathrm{rpm}$ for 1 h. $50 \mathrm{ml}$ of acetone was then added and the emulsion was stirred for a further $10 \mathrm{~min}$. The microspheres were isolated by centrifugation for $15 \mathrm{~min}$ at $2700 \mathrm{rpm}$, followed by decanting of the supernatant. The microspheres were then washed several times with acetone. After collection, the microspheres were washed with distilled water and phosphate-buffered saline to remove un- bound material. Subsequently the AHCMS were dehydrated with ethanol and sieved, giving a dry size of $10-25 \mu \mathrm{m}$.

Adriamycin loaded AHCMS (ADR-AHCMS) were prepared by $24 \mathrm{~h}$ incubation of $10 \mathrm{mg}$ of AHCMS in $1 \mathrm{ml}$ of adriamycin solution in distilled water $(5 \mathrm{mg} / \mathrm{ml})$ and subsequent washing with water and acetone. Payloads were calculated from the ADR depletion in the loading solution and the ADR recovery in the washing steps (Cremers et al., 1993b).

\subsection{Biocompatibility test}

ADR-AHCMS (44.93 mg) were resuspended in $1 \mathrm{ml}$ of ethanol by sonication. To the suspension, $51.6 \mathrm{ml}$ of $5 \% \mathrm{w} / \mathrm{v}$ glucose solution was added. After $2 \mathrm{~h}$ of rotation at $4^{\circ} \mathrm{C}$ in the dark, the microspheres were centrifuged and the supernatant was decanted. Fresh glucose solution was added. Three suspensions were prepared: 1.5, 0.75 and $0.375 \mathrm{mg} / \mathrm{ml}$. Empty AHCMS were resuspended in $5 \%$ glucose solution and diluted to concentrations of $1.0,0.5$ and $0.25 \mathrm{mg} / \mathrm{ml}$. The suspensions were stored overnight at $4^{\circ} \mathrm{C}$, until use.

Male Balb/c mice (body weight approx. $40 \mathrm{~g}$ ) were obtained from the Central Animal Laboratory, University of Groningen, The Netherlands. Seven groups of mice were injected with approx. $1 \mathrm{ml}$ of a microsphere suspension as depicted in Table 1. One more group of mice served as a control and received only the $5 \% \mathrm{w} / \mathrm{v}$ glucose

Table 1

Experimental set-up of the intraperitoneal biocompatibility test

\begin{tabular}{lclll}
\hline Code & $\begin{array}{l}\text { No. of } \\
\text { mice }\end{array}$ & Material & $\begin{array}{l}\text { Dose } \\
(\mathrm{mg})\end{array}$ & $\begin{array}{l}\text { Sampling time } \\
\text { (day) }\end{array}$ \\
\hline $\mathrm{C}$ & 15 & control & - & $1-2-3-5-7$ \\
$\mathrm{M} 1$ & 9 & AHCMS & 0.25 & $1-3-7$ \\
M2 & 9 & AHCMS & $0.5^{\text {a }}$ & $1-3-7$ \\
M3 & 15 & AHCMS & 1.0 & $1-2-3-5-7$ \\
AM1 & 15 & ADR-AHCMS & 0.375 & $1-2-3-5-7$ \\
AM2 & 15 & ADR-AHCMS & $0.75^{\text {a }}$ & $1-2-3-5-7$ \\
AM3 & 15 & ADR-AHCMS & 1.5 & $1-2-3-5-7$
\end{tabular}

a This dose was calculated based on an adriamycin dose of 5 $\mathrm{mg} / \mathrm{kg}$, which is the therapeutic dose used in the tumour model studies described below. 
solution. At different time intervals (Table 1) three mice of each group were killed and a peritoneal wash was carried out. The particles and cells in the peritoneal exudate were counted using a Coulter counter. Then the exudate of the three mice was pooled and the particles and cells were identified using light microscopy on sections cut after embedding in Technovit $7100^{\mathbb{B}}$ (Kulzer, Wehrheim, Germany). Five different groups were distinguished at identification: neutrophils, macrophages, lymphocytes, basophils/eosinophils and a group containing cells that could not be identified, microspheres, debris and dead cells which was categorized as 'other'. Their percentage in the LM sections was determined after classification of 200 cells per section.

\subsection{In vivo anti-tumour efficacy, L1210 mouse model}

Male $\mathrm{DBA}_{2}$ mice (7-8 weeks old, 23-26 g each) were purchased from Bantin \& Kingman Ltd, Hull, U.K. They were administered L1210 cells $\left(10^{5}\right)$ intraperitoneally, under light inhalational anaesthetic (Fluothane) on day 0 .

The mice were treated i.p. on days 1, 2 and 3, also under Fluothane anaesthetic, between 14:00 and 15:00 to minimize circadian variations. Control animals received $0.1 \mathrm{ml}$ injections of $5 \% \mathrm{w} / \mathrm{v}$ glucose solution. Animals receiving free ADR were administered either 5 or $10 \mathrm{mg} / \mathrm{kg}$ daily in glucose solution (0.1-0.2 ml). ADR-AHCMS was formulated as described above and administered i.p. at a dose of either 5 or $10 \mathrm{mg} / \mathrm{kg} \mathrm{ADR}$ on each day.

Mice were monitored closely and weighed daily. Any animal losing $20 \%$ of body weight was killed immediately. Similarly, animals showing either obvious discomfort or extensive tumour burden (usually reflected as a weight greater than 34 g) were also killed at once. Survival was monitored up to 100 days postadministration.

\subsection{In vivo anti-tumour efficacy, CC531 rat model}

Male Wag/Rij rats, 8-12 weeks old and weighing $220-260 \mathrm{~g}$ at the time of the experiments, were bred at the animal department of
The Netherlands Cancer Institute (Amsterdam, The Netherlands) under specific pathogen-free (SPF) conditions. The animals were kept on a 12 $\mathrm{h}$ light $/ 12 \mathrm{~h}$ dark cycle and fed standard rat chow and plain tap water ad libitum. Rats were anaesthetized with ether. After preparation for operation, a $1 \mathrm{~cm}$ incision was made into the median ventral abdominal wall, at about the transition of the upper and lower quadrants. A small part of the small intestines was exposed and a tumour disc, with a diameter of $3 \mathrm{~mm}$ and a thickness of $1.5 \mathrm{~mm}$, was implanted by a haemoclip fixation on the distal part of the mesentery. The tumour disc was obtained from the viable parts of subcutaneous CC531 tumours. The bowel was repositioned and the abdomen closed by three to four interrupted sutures. For assessing i.p. tumour growth a new laparotomy was performed at each measurement made at 2 weekly intervals. The size of the tumour was assessed by measuring three diameters of the tumour using Vernier calipers. The geometric mean of the three values was then calculated and used as the size estimate, since this gives a better estimate of volume for non-spheroid tumours. The overall mean and SD were then calculated from the geometric means of tumours in each group at set time points.

The tumour was implanted at day -11 . Animals were treated in three groups of four rats each and one group of five animals (control) on day 0 . All animals were administered $20 \mathrm{ml}$ of solution or suspension. The control animals received $5 \% \mathrm{w} / \mathrm{v}$ glucose solution. The first treatment group was administered free ADR at a dose of $5 \mathrm{mg} / \mathrm{kg}$. The second and third group were treated with ADR-AHCMS at doses of 5 and 10 $\mathrm{mg} / \mathrm{kg}$ of ADR, respectively. Tumour growth was determined at days $-5,7,21,35$ and 49 .

\section{Results and discussion}

AHCMS and ADR-AHCMS were prepared according to standard procedures as previously described by Cremers et al. (1993a,b). ADR release from ADR-AHCMS upon suspension of the microspheres in aqueous medium was as described previously. The amount of drug released 


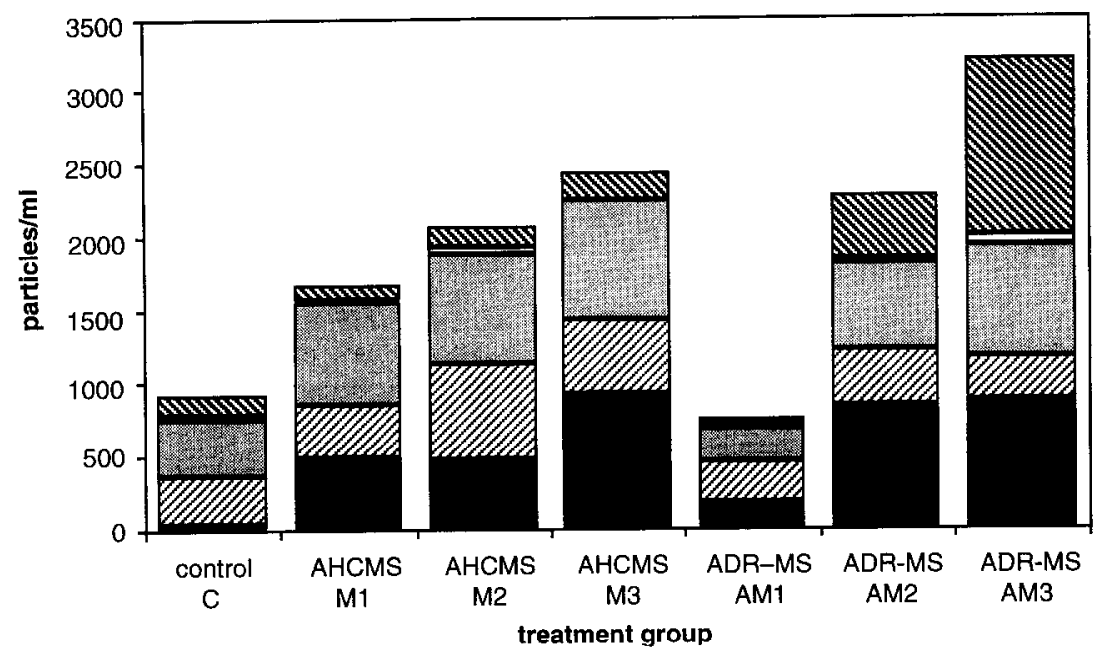

Fig. 1. Number of particles measured in peritoneal exudate, 1 day after i.p. administration of microspheres in Balb/c mice. (a) Neutrophils; ( $)$ lymphocytes; ( ) macrophages; ( $\square$ ) basophils/eosinophils; ( $)$ other (codes explained in Table 1).

varied between 2 and $30 \% \mathrm{w} / \mathrm{w}$ of the incorporated drug depending on the batch of ADRAHCMS used. This was taken into account in the preparation of the injections.

\subsection{Intraperitoneal biocompatibility test}

The microsphere concentration of the suspensions used in the i.p. biocompatibility experiments is based on a therapeutically applied ADR dose of $5 \mathrm{mg} / \mathrm{kg}$. The mice seemed to be unaffected by the i.p. administration of the microsphere suspensions, except for those receiving the highest ADR-AHCMS dose (10 mg/kg, AM3). These mice seemed to be less lively on the first day after administration. The peritoneum of these mice showed some milky spots, indicating necrosis at sites where the microspheres adhered to the peritoneum. It was also noticed that up to day 3 after administration of ADR-AHCMS, the supernatant of the peritoneal exudate was coloured red. This indicates the presence of free adriamycin or metabolites. At day 7 only the pellet obtained after centrifugation of the peritoneal exudate was coloured.

Fig. 1 shows the number and identification of particles and cells measured in the i.p. exudates on day 1. From Fig. 1 it can be seen that there is a dose-dependent inflammatory response in the case of empty AHCMS as well as ADR-AHCMS: In both cases the infiltration of cells increases with increasing dose. This can also be observed from Fig. 2 which shows the neutrophils measured after administration of particles, standardized with respect to control animals. It can be seen that the dose dependence of the response to the ADR-AHCMS lasts for a few days.

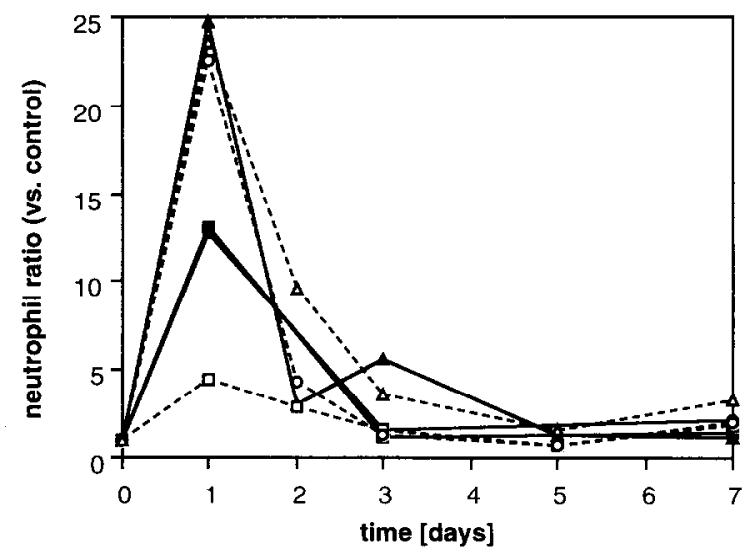

Fig. 2. Number of neutrophils measured after i.p. administration of microspheres in Balb/c mice, relative to controls. (a)

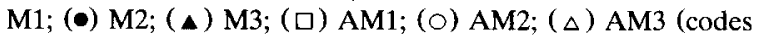
explained in Table 1). 


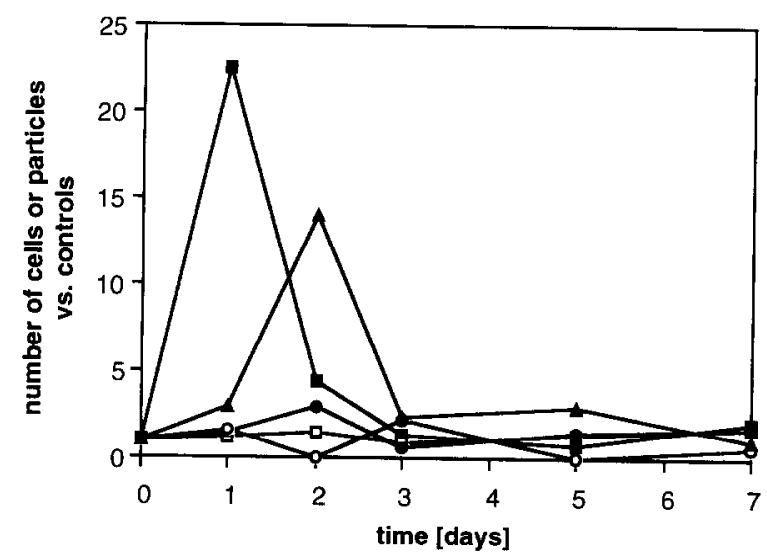

Fig. 3. Number of cells and particles after i.p. administration of $0.75 \mathrm{mg}$ ADR-MS (AM2) in male Balb/c mice, relative to controls. ( $\square$ ) Neutrophils; ( $\square$ ) lymphocytes; (•) macrophages; (O) basophils/eosinophils; ( $\Delta$ ) other.

An acute inflammatory response is characterized by the infiltration of primarily neutrophils and to a lesser extent, of macrophages. The increase in cells and particles as shown in Fig. 3, with a predominant increase in the number of neutrophils, is typical of an acute inflammatory response. Fig. 3 shows the amounts of cells and particles after i.p. administration of ADRAHCMS at the 'normal dose', relative to the controls. At day 1 the neutrophil level is increased significantly. The number of lymphocytes and basophils/ eosinophils, which is an indication for immunological and allergic reactions, is barely increased.

Fig. 3 also shows a significant increase in unidentifiable cells and debris (categorized as 'other'), mainly at day 2 . This phenomenon only occurred with ADR-AHCMS at normal and at double dose (AM2 and AM3, see also Fig. 1). This increase is most likely due to the cytotoxicity of the ADR, causing more cell death at higher doses. At day 2, the peritoneal infiltration was still characterized by an increased number of neutrophils, although the response was already strongly reduced. At day 3 the response was further decreased and could only be observed with the highest doses of microspheres and at days 5 and 7 no significant responses were observed (data not shown). Viewed overall, these
Table 2

Survival of mice inoculated with $\mathrm{L} 1210$ cells, after treatment with ADR or ADR-AHCMS

\begin{tabular}{|c|c|c|c|}
\hline Treatment ${ }^{a}$ & $\begin{array}{l}\text { Median } \\
\mathrm{l} / \mathrm{C} \mathrm{b}^{\mathrm{b}} \\
(\%)\end{array}$ & $\begin{array}{l}\text { Alive at } \\
\text { day } 100\end{array}$ & $\begin{array}{l}\text { Signifi- } \\
\text { cance }\end{array}$ \\
\hline Free ADR, $5 \mathrm{mg} / \mathrm{kg}$ & 155 & $1 / 5(20 \%)$ & - \\
\hline Free ADR, $10 \mathrm{mg} / \mathrm{kg}$ & 45 & $0 / 5 \quad(0 \%)$ & + \\
\hline ADR-AHCMS, $5 \mathrm{mg} / \mathrm{kg}$ & 236 & $2 / 5(40 \%)$ & + \\
\hline ADR-AHCMS, $10 \mathrm{mg} / \mathrm{kg}$ & 209 & $0 / 5 \quad(0 \%)$ & + \\
\hline
\end{tabular}

angle administration dose; animals were adminstered three doses.

${ }^{\mathrm{b}} \mathrm{T} / \mathrm{C}$ values calculated with control median $=11$ days; mean $=13$ days.

${ }^{c}$ Differences, as compared with controls, are significant at $p<0.05$ levels as determined by log-rank test.

acute inflammatory responses are quantitatively very slight and they suggest that the AHCMS and ADR-AHCMS are well tolerated after i.p. administration to mice.

\subsection{L1210 tumour-bearing mouse model}

The results of the anti-tumour efficacy investigation of ADR-AHCMS in L1210 i.p. inoculated mice are listed in Table 2 and are shown in Fig. 4. Median survival times are shown in Table 2, whereas the graph shows the survival of the mice. The controls (sham-treated animals) showed rapid

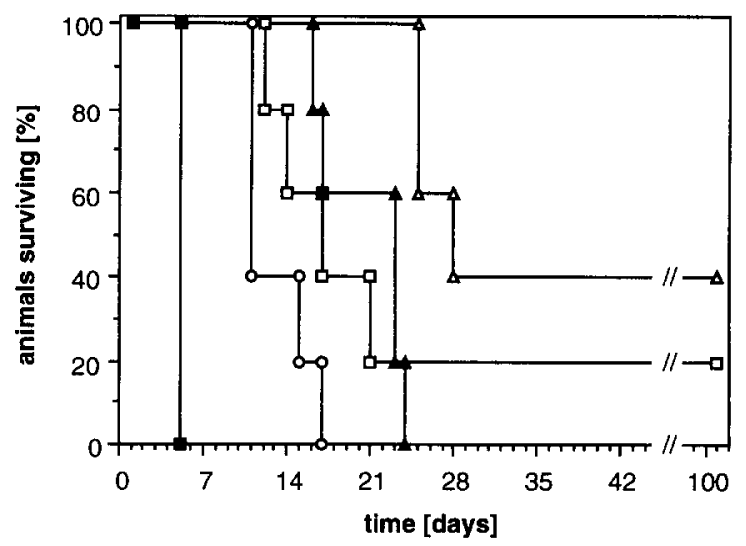

Fig. 4. Survival time of DBA2 mice inoculated i.p. with L1210

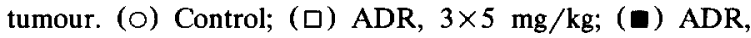
$3 \times 10 \mathrm{mg} / \mathrm{kg}$; $(\Delta)$ ADR-AHCMS, $3 \times 5 \mathrm{mg} / \mathrm{kg}$; ( $\Delta$ ) ADRAHCMS, $3 \times 10 \mathrm{mg} / \mathrm{kg}$. 
weight gain, beginning on day 8; all animals died from tumour burden. Animals treated with free ADR $(3 \times 10 \mathrm{mg} / \mathrm{kg})$ showed weight loss indicative of severe toxicity and were killed on day 5 . Those receiving the optimum therapeutic dose of free $\mathrm{ADR}(3 \times 5 \mathrm{mg} / \mathrm{kg})$ died from a mixture of tumour burden and toxicity with one animal still alive at day 100 (Fig. 4). The increase in survival times with respect to controls was not significant at a $p<0.05$ level as determined using a log-rank test (Table 2).

Animals receiving ADR-AHCMS were treated with three doses of either 5 or $10 \mathrm{mg} / \mathrm{kg}$. Those receiving $10 \mathrm{mg} / \mathrm{kg}$ demonstrated a substantial decrease in toxicity compared with the same dose of free drug. All animals showed some signs of toxicity like peritoneal oedema and weight loss although none met the criteria for early killing. The animals showed some recovery from these effects which were worst on about day 5 , although all eventually succumbed to treatment-related deaths. On autopsy there were no signs of any tumour burden in these mice. Animals treated with $3 \times 5 \mathrm{mg} / \mathrm{kg}$ of $\mathrm{ADR}$ as ADR-AHCMS showed only slight toxicity effects, with just a small initial fall in body weight. They appeared outwardly healthy for the first 20-25 days of the experiment. On about day 18 some animals began to show a regular increase in weight, and tumours were manifest in three animals on day 24 . Tumours then grew rapidly. Two animals were free of tumour and still alive at day 100 . Treatment with ADR-AHCMS at both doses improved the survival of mice significantly, as compared with controls (Fig. 4 and Table 2). Treatment with empty AHCMS did not significantly increase the survival time of L1210 inoculated mice as compared to untreated controls (data not shown).

\subsection{CC531 tumour-bearing rat model}

CC531 tumour growth curves are shown in Fig. 5. The plots show that i.p. treatment with 5 $\mathrm{mg} / \mathrm{kg}$ free ADR reduced the tumour growth significantly. Treatment with $5 \mathrm{mg} / \mathrm{kg}$ ADRAHCMS reduced tumour growth even more. $\Lambda \mathrm{t}$ day 35 , two out of three surviving animals were free of tumour. All animals treated with the

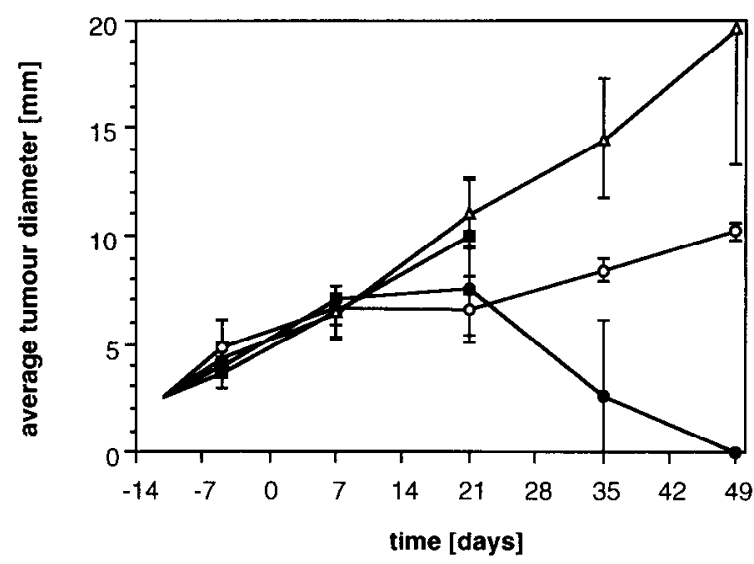

Fig. 5. Tumour growth delay of mesenteric CC531 tumours, implanted at day -11 in Wag/Rij rats, following i.p. treatment at day 0. Treatment: (O) ADR, $5 \mathrm{mg} / \mathrm{kg}$; (•) ADRAHCMS, $5 \mathrm{mg} / \mathrm{kg}$; ( ) ADR-AHCMS, $10 \mathrm{mg} / \mathrm{kg}$; $(\Delta)$ control. Each point represents mean; error bars indicate SD.

highest dose of ADR-AHCMS (10 mg/kg) had died from toxicity, evident as peritoneal oedema, by day 35 . In this group tumour growth over the first 20 days was not significantly different from the controls.

At day 21 one animal in the ADR-treated group and one animal in the ADR-AHCMS (10 $\mathrm{mg} / \mathrm{kg}$ ) group had died. Most other animals in these groups showed severe ascites. This was also noticed in the ADR-AHCMS ( $5 \mathrm{mg} / \mathrm{kg}$ ) group at later stages. At day 21 only one animal in this group suffered from ascites and at day 35 one animal had died and the remaining animals all showed signs of ascites.

The cause of the ascites is still not completely clear. In a control experiment animals were treated with empty AHCMS. This treatment did not have any effect on the tumour growth. None of the animals showed any signs of ascites. This implies that the ascites is ADR-related. Los et al. (1990) treated i.p. CC531 tumour-bearing Wag/ Rij rats intraperitoneally with ADR at a dose of 4 $\mathrm{mg} / \mathrm{kg}$. At this dose, tumour growth was initially delayed. At day 21, however, tumours started growing at a rate comparable to that of controls. The authors did not report any adverse effects due to $\mathrm{ADR}$ administration. This suggests that the applied dose $(4 \mathrm{mg} / \mathrm{kg})$ was safe in terms of 
toxicity, but less effective in tumour growth control than the treatment $(5 \mathrm{mg} / \mathrm{kg})$ applied here. Ozols et al. (1982) reported that the dose-limiting factor in intraperitoneal ADR in patients was chemical peritonitis. Treatment at concentrations greater than $36 \mu \mathrm{M}$ induced sterile ascites and peritoneal adhesions. Hence, intraperitoneal ADR toxicity is dose dependent as well as species dependent. In the case of rats, ascites was already evident at the $5 \mathrm{mg} / \mathrm{kg}$ dose, in the case of both free drug and ADR-AHCMS. In the L1210 mouse model, acute toxicity was observed with free ADR only at a dose of $3 \times 10 \mathrm{mg} / \mathrm{kg}$. Long-term effects indicated by ascites were only observed after $3 \times 10 \mathrm{mg} / \mathrm{kg}$ ADR-AHCMS treatment, not at the therapeutically applied dose of $3 \times 5 \mathrm{mg} / \mathrm{kg}$ ADR-AHCMS.

\section{Conclusions}

The intraperitoneal biocompatibility test in male Balb/c mice showed that empty AHCMS provoked only a mild dose-dependent inflammatory response, indicated by the infiltration of predominantly neutrophils. Incorporation of ADR into the AHCMS did not significantly enhance this response. At a drug dose of $10 \mathrm{mg} / \mathrm{kg}$, however, a greater extent of cell death was initially observed, probably due to the presence of high amounts of ADR.

The L1210 tumour-bearing mouse model and the CC531 tumour-bearing rat model both showed an increase in antitumour efficacy when the drug was formulated in AHCMS. The administration of ADR-AHCMS instead of ADR reduced the acute toxicity in both models. Higher drug doses were initially tolerated. At a dose of $3 \times 10$ $\mathrm{mg} / \mathrm{kg}$, however, mice developed ascites. In rats this was observed at lower doses $(5 \mathrm{mg} / \mathrm{kg})$.

It is encouraging that formulation of ADR in AHCMS increases the antitumour activity of ADR against two different types of tumour model. There appears to be a balance between reduction of the acute toxicity and induction of chemical peritonites and ascites as a long-term effect. This calls for more research directed towards the improvement of dose and dosage schedules of mi- crosphere drug delivery systems in i.p. chemotherapy.

It might be expected that regional therapy with a particulate formulation would show particularly good activity against tumour models which tend to grow in the omentum (eg. L1210), since this is also known to be the main site of accumulation of particles injected intraperitoneally (Seymour et al., 1991). However, the good activity demonstrated against solid CC531 tumours also implicates a component of sustained drug release.

\section{Acknowledgements}

The authors wish to acknowledge The Netherlands Organization for Scientific Research (NWO) and Theratech Inc., Salt Lake City, UT, for financially supporting this research and Farmitalia Carlo Erba for the kind gift of adriamycin.

\section{References}

Allen, L., On the penetrability of the lymphatics of the diaphragm. Anat. Rec. 124 (1956) 639-658.

Bouvier, G., Penn, R.D., Kroin, J.S., Beique, R. and Guerard, M.J., Direct delivery of medication into a brain tumor through multiple chronically implanted catheters. Neurosurgery, 20 (1987) 286-291.

Brem, H., Polymers to treat brain tumours. Biomaterials, 11 (1990) 699-701.

Cremers, II.F.M., Feijen, J., Kwon, G., Bae, Y.II., Kim, S.W., Noteborn, H.P.J.M. and McVie, J.G., Albumin-heparin microspheres as carriers for cytostatic agents. J. Controlled Release, 11 (1990) 167-179.

Cremers, H.F.M., Kwon, G.S., Bae, Y.H., Kim, S.W., Verrijk, R., Noteborn, H.P.J.M. and Feijen J., Preparation and characterization of albumin-heparin microspheres. Biomaterials, (1993a) in press.

Cremers, H.F.M., Verrijk, R., Noteborn, H.P.J.M., Kwon, G.S., Bae, Y.H., Kim, S.W. and Feijen J., Adriamycin loading and release characteristics of albumin-heparin conjugate microspheres. J. Controlled Release, (1993b) in press.

Duncan, R., Kopeckova, P., Strohalm, J., Hume, I.C., J., Loyd, J.B. and Kopecek, J., Anticancer agents coupled to $N$-(2-hydroxypropyl) methacrylamide copolymers: 2. Evaluation of daunomycin conjugates in vivo against L1210 leukemia. Br. J. Cancer, 57 (1988) 147-156.

Gillett, R. and Gull, K., Glutaraldehyde - Its purity and stability. Histochemie, 30 (1972) 162-167. 
Heller, J., Maa, Y.F., Wuthrich, P., Ng, S.Y. and Duncan, R., Recent developments in the synthesis and utilization of poly(ortho esters). J. Controlled Release, 16 (1991) 3-14.

Hennink, W.E., Feijen, J., Ebert, C.D. and Kim, S.W., Covalently bound conjugates of albumin and heparin: Synthesis, fractionation and characterization. Thromb. Res., 29 (1983) $1-13$.

Howell, S.B., Pfeifle, C.L., Wung, W.E., Olshen, R.A., Lucas, W.E., Yon, J.L. and Green, M., Intraperitoneal cisplatin with systemic thiosulfate protection. Ann. Int. Med., 97 (1982) 845-851.

Knapp, R.C., St. John, E. and Bast, R.C., Jr, A review of intraperitoneal therapy of human ovarian carcinoma. Peritoneal Dialysis Bull., 3 (1983) 59-62.

Kwon, G.S., Bae, Y.H., Kim, S.W., Cremers, H. and Feijen, J., Preparation and characterization of microspheres of albumin-heparin conjugates. J. Colloid Interface Sci., 143 (1991) 501-512.

Langer, R., Polymer implants for drug delivery in the brain, $J$. Controlled Release, 16 (1991) 53-60.

Los, G., Nagel, J.D. and McVie, J.G., Anti-tumour effect of cisplatin, carboplatin, mitoxantrone, and doxorubicin on peritoneal tumour growth after intraperitoneal and intravenous chemotherapy: A comparative study. Selective Cancer Ther., 6 (1990) 73-82.

Markman, M. and Howell, S.B., The intracavitary administration of cytarabine to patients with nonhematopoietic malignancies: An update, Semin. Oncol., 14 (1987) 116-120.

Miyazaki, S., Hashiguchi, N., Yokouchi, C., Takada, M. and Hou, W.-M., Antitumour effect of fibrinogen microspheres containing doxorubicin on Ehrlich ascites carcinoma. $J$. Pharm. Pharmacol., 38 (1986) 618-620.

Ozols, R.F., Young, R.C., Speyer, J.L., Sugarbaker, P.H., Greene, R., Jenkins, J. and Myers, C.E., Phase I and pharmacological studies of adriamycin administered intraperitoneally to patients with ovarian cancer. Cancer Res., 42 (1982) 4265-4269.
Pizzoferrato, A., Vespucci, A., Ciapetti, G., Stea, S. and Tarabusi, C., The effect of injection of powdered biomaterials on mouse peritoneal cell populations. J. Biomed. Mater. Res., 21 (1987) 419-428.

Regelson, W., Advances in intraperitoneal (intracavitary) administration of synthetic polymers for immunotherapy and chemotherapy. J. Bioactive Compatible Polym., 1 (1986) 84-107.

Seymour, L.W., Duncan, R., Strohalm, J. and Kopecek, J., Effect of molecular weight $\left(M_{\mathrm{w}}\right)$ of $N$-(2-hydroxypropyl) methacrylamide copolymers on body distribution and rate of excretion after subcutaneous, intraperitoneal, and intravenous administration to rats. J. Biomed. Mater. Res., 21 (1987) 1341-1358.

Seymour, L.W., Schacht, E. and Duncan, R., The effect of size of polystyrene particles on their retention within the rat peritoneal compartment, and on their interaction with rat peritoneal macrophages in vitro. Cell Biol. Int. Rep., 15 (1991) 277-286.

Ueno, N, Refojo, M.E. and Liu, L.H.S., Controlled release rate of a lipophilic drug (BCNU) from a refillable silicone rubber device. J. Biomed. Mater. Res., 16 (1982) 669-677.

Ulbrich, K., Subr, V., Seymour, L.W. and Duncan, R., Novel biodegradable hydrogels prepared using the divinylic crosslinking agent $\mathrm{N}, \mathrm{O}$-dimethacryloylhydroxylamine: 1 . Synthesis and characterization of rates of gel degradation and rate of release of model drugs in vitro and in vivo. (1992) submitted.

Wahl, R.L., Barrett, J., Geatti, O., Liebert, M., Wilson, B.S., Fisher, S. and Wagncr, J.G., The intraperitoneal delivery of radiolabelled monoclonal antibodies: Studies on the regional delivery advantage. Cancer Immunol. Immunother., 26 (1988) 187-201.

Zedeck, M.S. and Sternberg, S.S., A model system for studies of colon carcinogenesis: Tumour induction by a single injection of methylazoxymethanol acetate. J. Natl. Cancer Inst., 53 (1974) 1419-1421. 